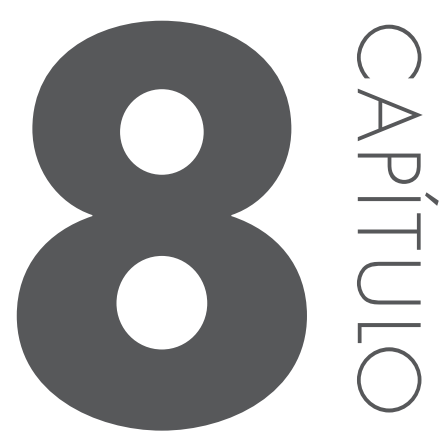

\title{
A EDUCAC̣ÃO AMBIENTAL E AS CONTRIBUIC̣ÕES DO ENSINO DE GEOGRAFIA E BIOLOGIA
}

Assis, Aiany Ruth Silva de ${ }^{*}$; Chaves, Manoel Rodrigues

Mestranda do Programa de Pós-Graduação em Geografia, Universidade Federal de Goiás - Campus Catalão. Departamento de Geografia - Geografia e Ordenamento do Território Professor Doutor do Instituto de Geografia, Universidade Federal de Goiás - Campus Catalão. Departamento de Geografia - Geografia e Ordenamento do Território * email: aianyassis@yahoo.com.br

\section{RESUMO}

A questão ambiental impõe às sociedades buscar novas formas de pensar e agir, encontrar novos caminhos que garantam a sustentabilidade ecológica. Atualmente, atravessa-se um período de intensas transformações do ambiente e o homem é o principal responsável pelo processo de modificação do ambiente. Os conhecimentos em Geografia e Biologia referente à Educação Ambiental (EA) propõem o desenvolvimento de posturas e valores pertinentes às relações entre os seres humanos entre eles e o ambiente. O objeto da pesquisa será o Colégio Estadual Dr Vasco dos Reis Gonçalves em Urutaí (GO) com os alunos da $3^{\mathrm{a}}$ série do Ensino Médio dos períodos matutino e noturno, dessa 
forma, pretende-se discutir as contribuições do ensino de Geografia e Biologia em relação à possibilidade de trabalhar com a EA. A metodologia utilizada consta de pesquisa teórica, pesquisa documental e pesquisa de campo. A pesquisa teórica baseia-se também em revisões bibliográficas, busca-se na literatura informações disponíveis e relevantes sobre a temática abordada, na observação dos fatos tal como ocorre na realidade. A pesquisa documental consta da leitura de documentos da escola como o Projeto Político Pedagógico, Planos de aula dos professores de Geografia e Biologia do $3^{a}$ série do Ensino Médio através do SIAP (Sistema de Apoio ao Professor) e outros documentos que contribuem para a realização do trabalho. O método de coleta de dados utilizado foi realizado com base em entrevistas de grupo focal com participação de 26 alunos e através de questionários com a participação de 32 alunos. O questionário foi estruturado com doze perguntas, sendo sete subjetivas e cinco questões objetivas, duas delas eram totalmente fechadas e em três perguntas foi pedido para marcar e justificá-las. A entrevista de grupo focal contou com nove perguntas relacionadas às questões ambientais e relacionadas às questões do questionário.

Palavras-chave: educação ambiental; ensino de Geografia; ensino de Biologia

Assis, Aiany Ruth Silva de; Chaves, Manoel Rodrigues; "A EDUCAÇÃO AMBIENTAL E AS CONTRIBUIÇÕES DO ENSINO DE GEOGRAFIA E BIOLOGIA", p. 131-147 . In: Seminário de Pesquisa, Pós-Graduação e Inovação da Regional Catalão (2. : 2014 : Goiás) Coletânea Interdisciplinar em Pesquisa, Pós- Graduação e Inovação - Volume 1 : Estudos Ambientais, Território e Movimentos Sociais. Anais [livro eletrônico] / organizado por Adriana Freitas Neves, Idelvone Mendes Ferreira, Maria Helena de Paula, Petrus Henrique Ribeiro dos Anjos. São Paulo: Blucher, 2015. ISBN: 978-85-8039-109-1, DOI 10.5151/9788580391091-V1_Cap08 


\section{EDUCAC̣ÃO AMBIENTAL E O ENSINO DE BIOLOGIA}

A Biologia enquanto ciência unificada surgiu no início do século XIX. Antes disso existiram os botânicos que se dedicavam a estudar as plantas não como cientistas envolvidos em selecionar e classificar as espécies descobertas. Suas pesquisas eram realizadas como caráter de colecionar as espécies de plantas de determinada região.

Nessa vertente, não se pode deixar de fazer referência a um importante pesquisador, Alexander Humboldt, geógrafo naturalista que no ano de 1800 chegava a América do Sul e dedicou suas pesquisas à área da botânica, especificamente na elaboração de uma geografia botânica. Sobre Humboldt, Alves (2005) faz algumas considerações.

[...] característica que também esteve presente nos escritos de Humboldt, na medida em que sua principal preocupação, quando observava a natureza, era com a estética. Tal atitude é percebida em vários momentos de sua obra, principalmente quando descreve os elementos da paisagem, interpretando-os de uma maneira extremamente poética [...]. Humboldt foi o primeiro na Geografia a realizar um trabalho de campo sistemático, no qual propunha uma observação minuciosa dos elementos da paisagem, buscando na sua contemplação fazer a ligação do particular com o que pode ser encontrado de mais geral, ou seja, preocupando-se constantemente em deslocar-se da individualidade dos lugares ou dos fenômenos para a universalidade. (ALVES, 2005, p. 69-74)

As considerações do autor deixam clara a importância de Humboldt para as ciências geográficas e biológicas a partir de sua observação e constante experimentação. A palavra biologia significa estudo da vida. Foi em 1801 e 1802 que Jean Baptiste Lamarck, evolucionista francês introduziu o termo biologia. De acordo com Ferreira (2007, p. 37) “[...] ainda que ignorado em seus dias na parte que mais valorizava em sua obra e mesmo refutado pela biologia atual, Lamarck foi causador de debates e controvérsias estimulantes e férteis entre a minoria de evolucionistas que viriam a ascender no final do século XIX”.

A Biologia se unificou com Charles Darwin, evolucionista britânico que marcou a história da evolução, pois, através dos conceitos dos caracteres descobertos por Lamarck, Darwin aperfeiçoou as teorias de Lamarck e descobriu que esses caracteres são transmitidos de geração para geração, que 
mais tarde descobriram serem essas características são hereditárias. O livro A Origem das Espécies de 1859 explica a diversidade de espécies na natureza, ressalta as transformações sofridas de uma espécie para outra. Tendo em vista a grande variabilidade genética, Darwin (2006) explica.

[...] uma grande variabilidade - termo onde sempre são incluídas as diferenças individuais - será evidentemente favorável à ação da Seleção Natural. Um grande número de indivíduos, apresentando maiores possibilidades de variações vantajosas num determinado tempo, compensará uma menor variabilidade em cada indivíduo e será, acredito, um elemento muito importante para o sucesso. (DARWIN, 2006, p. 339)

Darwin explica que os organismos vivos produzem grande quantidade de unidades reprodutivas e que na maioria das espécies, o número de indivíduos permanece mais ou menos constante. Os organismos de uma população original apresentam variações físicas e comportamentais, essas variações podem ser transmitidas aos descendentes.

A seleção natural é uma teoria darwinista muito aceita que deixa evidente que o ambiente seleciona as espécies. As espécies que não se adaptarem a determinadas condições oferecidas pelo ambiente deixam de existir. A teoria deixa claro que a natureza contribui para o aprimoramento das espécies ao longo das gerações, a partir da adaptação da espécie a um determinado ambiente.

O processo histórico da Biologia contribui para a compreensão dos conceitos biológicos de ambiente e dos ecossistemas terrestres, que precisam estar em equilíbrio dinâmico. A conservação dos ecossistemas para a sobrevivência dos seres vivos e as ações antrópicas degradantes trazem consequências para a espécie humana, para as outras espécies, enfim para todo o ambiente.

Torna-se importante considerar a historicidade das questões ambientais, evidenciar o surgimento da Educação Ambiental, o que permite compreender a significação humana no ambiente, ampliar as percepções do senso comum e os preconceitos, visões limitadas com as quais muitas vezes as pessoas possuem em relação à natureza.

O homem não se considera inferior à natureza, por isso apropria dos recursos naturais por se considerar num patamar superior à natureza (visão antropocêntrica). O homem enxerga a natureza como um bem inesgotável e por isso causa desequilíbrios nos ecossistemas. Com essa mesma visão Duvoisin (2002, p. 91) ressalta que "[...] à medida que o ser humano foi se distanciando 
da natureza e passou a encará-la como uma gama de recursos disponíveis, começaram a surgir os problemas socioambientais ameaçando a sobrevivência do nosso planeta".

A Educação Ambiental é uma proposta que altera a educação como a conhecemos, com práticas pedagógicas que contemplem a transmissão de conhecimentos em Ecologia. Importantes para a compreensão dos problemas relacionados com a interação dos seres vivos com o ambiente e envolver os alunos nas discussões sobre a questão ambiental. Odum (1988) esclarece que o conceito de ecologia

[...] é um campo reconhecidamente distinto da ciência desde 1900. A expressão deriva do grego oikos (casa) e logos (estudo). Assim, a ecologia seria o estudo do "ambiente da casa" e isso "inclui todos os organismos contidos nela e todos os processos funcionais que a tornam habitáveis". (ODUM, 1988, p. 1)

Tendo em vista esses aspectos, a Biologia é uma disciplina que busca enfocar as questões ambientais, por se preocupar com a ação dos seres vivos e em particular o homem nos ecossistemas, uma vez que a destruição dos ecossistemas prejudica as cadeias alimentares e assim prejudica o ambiente.

Para que os alunos desenvolvam as suas potencialidades e adote posturas pessoais e comportamentos sociais construtivos, o ensino de Biologia enquanto ciência da vida contribui com a sociedade ao mesmo tempo em que favorece a aquisição do saber ambiental. Reigota (1999) esclarece que,

[...] um dos principais equívocos em relação à educação ambiental escolar é vê-la como um substituto do ensino das disciplinas tradicionais, como Biologia e Ciências. O conteúdo dessas disciplinas permite que vários aspectos do meio ambiente sejam abordados, mas sua prática pedagógica mais tradicional procura transmitir conteúdos científicos ou, na sua versão mais moderna, construir conceitos científicos específicos dessas disciplinas, como se a transmissão e/ou construção de conhecimentos científicos si só fossem suficientes para que a educação ambiental se realizasse. (REIGOTA, 1999, p. 81)

Conhecer os princípios ambientais não se restringe ao estudo da natureza in loco, trata-se de levantar os problemas de um dado local. A partir da leitura desta realidade levar em consideração a contribuição da Biologia, com 
o propósito de diminuir os problemas diagnosticados e propor melhorias. Somente conhecendo o problema tem-se a possibilidade de contorná-los.

O ensino Biologia aliado a Educação Ambiental proporciona conhecimentos referentes às questões ambientais, dando suporte para que os alunos se tornem sensibilizados com os problemas ambientais, permite auto-questionamento que vão além da redução do desperdício de recursos naturais. Sobre as maneiras de interpretar a EA na esfera pedagógica, Carvalho (2012) comenta.

[...] as trilhas interpretativas de inspiração naturalista ilustram muito adequadamente o entendimento de EA como difusão de conhecimento da Biologia ou de Ciências. Embora se chamem interpretativas, tais trilhas, em sua concepção pedagógica, poderiam antes ser denominadas explicativas. Não se trata aqui de negar a importância do conhecimento e das explicações biológicas na EA, mas de alertar para o risco de reduzir o ato educativo a um repasse de informações provenientes das ciências naturais, sem correlacionar esse conhecimento com a complexidade das questões ambientais que o circundam e o constituem. (CARVALHO, 2012, p. 81)

O educar ambientalmente é uma iniciativa educativa que vai além das responsabilidades individuais. $\mathrm{O}$ trabalho em conjunto precisa ser estabelecido nas escolas para a formação de cidadãos de forma inalienável e para que consiga desvelar a realidade. $\mathrm{O}$ ensino de Biologia necessita buscar por uma metodologia calcada nas abordagens interdisciplinares das disciplinas científicas para produzir identidades individuais e coletivas no espaço escolar. Valerias (2003) comenta a respeito da EA e a contribuição da Biologia.

[...] torna-se difícil fazer um corte no processo histórico e definir com precisão o início da Educação Ambiental como uma nova concepção educacional, no entanto afirmarmamos que a Biologia tem sido um apoio inicial, [...] as diferentes reuniões que marcam a evolução da EA e das inúmeras experiências locais e individuais, nos permite estabelecer as etapas pelas quais foi evoluindo historicamente esta disciplina. (VALERIAS, 2003, p. 155)

Para uma melhor compreensão da questão ambiental, seus conceitos e seus problemas, o ensino de Biologia possibilita a compreensão do funcionamento dos ecossistemas terrestres e cada vez mais o homem utiliza dos conhecimentos 
biológicos para melhorar as relações dos seres vivos com a natureza. Rezende et al (2013) explicam a relação do ensino de Biologia à EA.

[...] a EA pode ser uma importante aliada para a Biologia no processo formativo de compreensão da vida, do Meio Ambiente como um conjunto das inter-relações entre o mundo natural e o mundo social. Acreditamos em uma possível relação de compartilhamento de saberes e princípios entre a Biologia e a EA, mas, sobretudo, reconhecemos que não apenas os conhecimentos biológicos são necessários ao trabalho da EA. (REZENDE, et al, 2013, p. 214)

A metodologia do ensino de Biologia contribui para a fundamentação dos princípios da EA. O conhecimento não pode ser fragmentado, mas precisa dos conceitos que são essenciais para uma sólida fundamentação teórica. Nesse sentido, cada professor pode buscar alternativas para inovar suas práticas pedagógicas para que a EA conquiste um lugar de destaque no cenário educativo.

Nessa perspectiva Reigota e Tamoio (2011, p. 17) consideram que “[...] as práticas pedagógicas ainda permanecem restritas a ações isoladas de alguns professores, que realizam atividades que mesmo de relevância, na maioria das vezes, não são capazes de apreender os objetivos educacionais". Perandré (2007) contribui a respeito dos propósitos da EA.

[...] a finalidade da EA é restabelecer a complexa interação entre sociedade e natureza. A ecologia e outras ciências correlatas influenciaram grande parte do conhecimento existente sobre o meio ambiente. Assim, o que era suficiente para satisfazer às necessidades do passado passou a ser insuficiente para embasar a tomada de decisões na organização ambiental da época. (PERANDRÉ, 2007, p. 32)

Os conceitos biológicos são muitos, o que deve ter em mente é o objetivo de cuidados com a natureza, o cuidar do ambiente. É importante a assimilação dos conceitos biológicos pelos alunos e inserir esses conceitos em seu cotidiano. A Biologia proporciona condições de reconhecimento dos elementos que compõem o ambiente, investigarem as raízes dos problemas ambientais de maneira a avaliar os fenômenos antrópicos sob a natureza e a mudança do estado de equilíbrio do ecossistema natural.

Pode-se observar ainda falando sobre conceitos biológicos que se usa o 
conceito ecossistema como sinônimo de ambiente. O ecossistema refere-se às condições com aspectos físicos e biológicos que represente determinado ecossistema. Cada ecossistema possui fatores vivos e não-vivos característicos. Assim, de acordo com Guimarães (2010) faz-se importante a formação dos professores, uma vez que

[...] é importante que a biologia ande de mãos dadas com as novas ciências da complexidade que nos ensinam a procurar padrões globais em vez de especificidades reducionistas. A formação do professor de biologia deve perceber a importância e relevância dessa abordagem complexa para dar conta de entender a complexidade dos problemas ambientais atuais. (GUIMARÃES, 2010, p. 106)

Nesse viés, o autor considera a complexidade dos seres vivos. Os professores de Biologia têm papel preponderante na educação para o ambiente, não sendo os únicos responsáveis na transmissão da prática ambiental, mas a responsabilidade precisa ser dividida com os professores das ciências afins, para desenvolver a competência dos educandos e contextualizar os conhecimentos.

$\mathrm{Na}$ perspectiva da Educação Ambiental, os Parâmetros Curriculares Nacionais de Biologia trazem todos os conteúdos contextualizados para que os alunos relacionem enquanto seres integrantes da natureza e compreenda a relação dos outros seres vivos com a mesma. Como estratégias do ensino de Biologia, Brasil (2000, p. 13) sugere que "[...] utilizar elementos e conhecimentos científicos e tecnológicos para diagnosticar e equacionar questões sociais e ambientais”.

A Biologia permite a compreensão da natureza viva, valorização da vida em sua diversidade. Foca conteúdos referentes à temática ambiental questões relacionadas à poluição ambiental, interações dos seres vivos com o ambiente.

Para Brasil (2000, p. 15) “[...] o ambiente, que é produto das interações entre fatores abióticos e seres vivos, pode ser apresentado num primeiro plano e é a partir dessas interações que se pode conhecer cada organismo em particular e reconhecê-lo no ambiente e não vice-versa". Todas as questões referentes ao conhecimento do ambiente favorecem a compreensão da dimensão espaço-temporal do estabelecimento de ecossistemas.

Para a assimilação dos conteúdos referentes às questões ambientais que os PCNs trazem, faz-se necessário a diversificação de metodologias por parte do professor que precisa esclarecer conceitos, estimular a investigação 
pelos alunos para que o conhecimento seja satisfatório. Os PCNs propõem soluções para os problemas do cotidiano e relaciona as diversas disciplinas na compreensão dos processos biológicos.

De acordo com Pedrini (2000, p. 15) “[...] a EA é considerada como saber construído socialmente e caracteristicamente multidisciplinar na estrutura, interdisciplinar na linguagem e transdisciplinar na ação não pode ser área profissional específica de nenhuma especialidade do conhecimento humano". A EA é uma dimensão da educação que promove a transformação das pessoas e dessa forma contribui para a prática social através da aquisição de novos hábitos por parte dos educandos. Sobre a interdisciplinaridade, assim, Fazenda (1993) faz importantes considerações.

[...] a atitude interdisciplinar não está na junção de conteúdos, nem na junção de métodos; muito menos na junção de disciplinas, nem na criação de novos conteúdos produtos dessas funções; a atitude interdisciplinar está contida nas pessoas que pensam o projeto educativo. (FAZENDA, 1993, p. 64)

Os professores de Biologia precisam se aproximar com outras áreas do conhecimentono sentido de tornara temática ambiental emevidência permanente, tendo sempre a intenção didática em manter o caráter interdisciplinar do saber ambiental. Nessa perspectiva, Guimarães (2010) comenta que

[...] o saber ambiental complexo, ou a incorporação dessa dimensão na formação crítica dos professores de Biologia possa inscrever-se dentro da (re) significação da vida (objeto de estudo da própria biologia) e possa contribuir com a reconstrução do mundo atual. (GUIMARÃES, 2010, p. 58)

Diante do exposto, a sociedade moderna precisa ser alicerçada, estruturada de acordo com as mudanças da realidade social e construir um caminho sólido que conduza a uma nova concepção de mundo.

\section{GEOGRAFIA E EDUCAC̣ÃO AMBIENTAL}

A Geografia moderna tem como um dos pais Alexander Humboldt, geógrafo que trouxe contribuições importantes para as várias áreas do conhecimento como a Biologia. Humboldt teve várias influências das correntes iluministas de August 
Comte. Sobre a influência iluminista, Dagnino (2008, p. 70) comenta que "[...] Humboldt se apresenta como um cientista sensível e atento às teorizações de Kant de várias formas. Com relação a este caminho intermediário que torna as idéias kantianas tão dúbias, Humboldt propôs saídas bastante interessantes”.

As ideias iluministas contribuíram com Humboldt no processo de percepção do mundo durante as pesquisas de campo. Em seus estudos, o pesquisador procurou compreender e fazer descrições da natureza. Nessa linha de raciocínio, para Ricotta (2003, p. 59) Humboldt dizia que “[...] o que nomeio como descrição física do mundo não pretende alcançar uma categoria de uma ciência racional da natureza; é a apreciação reflexiva dos fenômenos dados através da empiria, tomados como fenômenos do todo da natureza".

Diante do exposto, pode-se considerar que a Geografia contribui na perspectiva ambiental e vem sendo trabalhada na vertente socioambiental, na relação homem-natureza. Segundo Klein (2002, p. 126), “[...] o ensino em equipe é um poderoso mecanismo de preparação dos professores e uma forma importante de revitalização intelectual por meio do aprendizado em colaboração.” Em pesquisa realizada com os professores de Geografia sobre Educação Ambiental Bortolozzi e Perez Filho (2012) assinalam que:

[...] predomina então um acompanhamento próprio dos meios de difusão do sistema de comunicação social, ou seja, meios de comunicação de massa, sendo que o sistema de educação formal deixa a desejar resultando na própria falta de consciência ambiental e na inadequada formação acadêmica, apresentadas pela maioria dos professores pesquisados, pois eles não estão acompanhando a questão ambiental pelos mecanismos que deveriam ser próprios da educação em todos os níveis, principalmente pela difusão, por exemplo, por meio de textos, livros paradidáticos, cursos, palestras, simpósios, encontros e congressos. Mais grave ainda tornase o quadro, ao considerar-se que na imprensa escrita e falada predominam, principalmente na TV, os temas amplos envolvendo meio ambiente, ecologia, equilíbrio ecológico, extinção de espécies que, raramente apresentando uma abordagem socioambiental, eliminam a explicação sobre as causas dos problemas. (BORTOLOZZI; PEREZ FILHO, 2012, p. 52)

Nesse viés de estudo da Geografia com a questão ambiental, considera-se as dificuldades que os professores enfrentam para transmitir a problemática ambiental compatível com a realidade. Os enfoques dados pelos professores 
devem partir dos problemas locais e abranger também os problemas ambientais globais.

Nesse sentido, os educadores ambientais desempenham um importante papel na sociedade enquanto formadores de opiniões por serem detentores de propostas pedagógicas, percepção da complexidade ambiental e das relações sociais humanas sob os diferentes aspectos culturais. Assim, Leff (2001a) discute que

[...] a complexidade da problemática ambiental implica uma revolução do pensamento, uma mudança de mentalidade, uma transformação do conhecimento e das práticas educativas, para se construir um novo saber, uma nova racionalidade que orientem a construção de um mundo de sustentabilidade, de equidade, de democracia [...]. Aprender a aprender a complexidade ambiental implica uma nova compreensão do mundo que problematiza os conhecimentos e saberes arraigados em cosmologias, mitologias, ideologias, teorias e saberes práticos que se encontram nos alicerces da civilização moderna, no sangue de cada cultura, no rosto de cada pessoa. (LEFF, 2001a, p. 196)

Ocorre que o debate sobre a problemática ambiental proporciona a formação de alguns preconceitos e a veiculação de algumas imagens distorcidas sobre as questões relativas ao ambiente em consequência do processo decisório sobre a apropriação e o uso dos recursos naturais de forma ecologicamente correta. Nesse viés, Leff (2001b, p. 49) relata que “[...] a destruição ecológica e o esgotamento dos recursos não são problemas gerados por processos naturais, mas determinados pelas formas sociais e pelos padrões tecnológicos de apropriação e exploração econômica da natureza”.

É pertinente sublinharque a adoção dessas ações prejudica o desenvolvimento econômico e interfere na manutenção da vida de futuras gerações, ainda incita a adoção de novos posicionamentos no que se refere à proteção e conservação ambiental. Layrargues (2001) discute a realidade e o processo de reflexão sobre os problemas ambientais, afirmando que:

[...] a estratégia da resolução dos problemas ambientais locais como metodologia da educação ambiental permite que dois tipos de abordagens possam ser realizadas: ela pode ser considerada tanto como um tema-gerador de onde se irradia uma concepção pedagógica comprometida com a compreensão e transformação 
da realidade; ou como uma atividade-fim, que visa unicamente a resolução pontual daquele problema ambiental abordado. (LAYRARGUES, 2001, p. 134)

As concepções mudam em função da problemática ambiental existentes em cada localidade frente às concepções de ambiente. É preciso identificar os problemas decorrentes da relação sociedade e natureza para que sejam feitas intervenções para procurar minimizar os problemas diagnosticados. Nesse viés, Carvalho (2012, p. 51) ressalta que "[...] a EA é herdeira direta do debate ecológico e está entre as alternativas que visam construir novas maneiras de os grupos sociais se relacionarem com o meio ambiente".

Os cuidados com o ambiente envolvem a preservação da vida, uma questão que requer reflexão e atitudes, merece o envolvimento dos educadores e outros atores sociais que reconheça que a natureza abriga o homem e essa relação necessita ser equilibrada. De acordo com Suertegaray $(2006$, p. 27) “[...] a questão ambiental pertinente também à geografia, não é sua exclusividade. Sua complexidade exige conjunção de olhares, dialógica e a superação da análise de objetos puros (específicos)".

Para que a transmissão de conhecimentos seja satisfatória e alcance bons resultados, os professores precisam trabalhar com esses conteúdos na teoria e na prática, considerando a relação conflituosa entre homem e natureza. Toledo (2003) explica a relação dos professores de Geografia com a Educação Ambiental.

[...] se por um lado, os profissionais de Geografia possuem incisivas e substanciais contribuições e participação de projeção histórica, na análise da questão ambiental e na formulação de um consistente projeto necessariamente transdisciplinar, sobre Educação Ambiental, por outro lado, as instituições acadêmicas geográficas brasileiras, [...] não possuem cursos específicos com o rótulo Educação Ambiental. (TOLEDO, 2003, p. 127)

Ao ressaltar o enfoque geográfico na Educação Ambiental, Bispo (2012, p. 53) considera que “[...] a educação geográfica tem uma contribuição importante na educação ambiental, na sensibilização dos alunos sobre o impacto do seu próprio comportamento, e suas atitudes, e é uma ciência que possui uma identidade marcante".

A questão ambiental possui importante atuação das ciências sociais como a Geografia, por considerar o homem como agente e ser afetado pelas alterações 
no ambiente. A EA é uma questão ampla que merece ser abordada de forma interdisciplinar para obter melhores resultados no ambiente escolar e fora dele. Nunes; Silva (2011) afirmam sobre a contribuição do ensino de Geografia.

[...] a Geografia permite o conhecimento da realidade social, econômica, cultural e ambiental. Portanto, a contribuição da Geografia é fundamental, para que o aluno enquanto indivíduo da sociedade possa compreender e desenvolver uma consciência crítica sobre a problemática ambiental. (NUNES; SILVA, 2011, p. 21)

A escola é um espaço, categoria geográfica que segundo Cruz (2012, p. 3) “[...] emergiu a partir do processo de solidificação da Geografia, como uma disciplina científica, exigindo assim, a construção de um sistema de categorias e conceitos particulares, com o objetivo de formular um conhecimento acerca dos fenômenos geográficos estudados".

A categoria espaço é a mais discutida nas ciências geográficas por formar o todo. É formado pelo conjunto das coisas e a sociedade que modificam e o transformam continuamente, não deve considerá-lo apenas como objeto e sim uma instância da sociedade.

\section{CONSIDERAC̣ÕES FINAIS}

Os alunos consideram conscientes da responsabilidade que têm com o meio ambiente, mas mesmo assim apresentam práticas incorretas com relação ao meio ambiente. Eles consideram que há relação entre Geografia e Biologia no conteúdo referente aos ecossistemas, conteúdo trabalhado pelos professores das duas disciplinas, como averiguado nos planos de aula dos professores da $3^{\mathrm{a}}$ série do Ensino Médio. As respostas dos alunos refletem a superficialidade de conhecimentos relacionados à Educação Ambiental e os referentes às questões ambientais.

A aproximação da escola com a comunidade é ineficiente no que se refere às questões ambientais. As mudanças precisam acontecer a partir da disseminação de conhecimentos sobre o cenário ambiental tendo em vista as reais necessidades de envolvimento e participação da sociedade em projetos promovidos pela escola.

As disciplinas responsáveis pela disseminação dessa questão, a Geografia e a Biologia não caminham juntas na escola. Precisa-se estabelecer diálogos entre 
as duas disciplinas para que exista o fortalecimento da Educação Ambiental na escola, buscar condições para que sejam efetivados o cumprimento dessa questão no PPP da escola, ou seja, inserir a temática ambiental e mais especificamente, a Educação Ambiental na teoria e na prática.

Todos os alunos citaram algum aspecto da Educação Ambiental na escola que refletem na falta de formação dos professores voltada para essa área influenciam no comportamento dos alunos. Os temas ambientais abstratos e amplos demais fogem da realidade perceptível dos alunos que estão concluindo a educação básica e partindo para o ensino superior e/ou para o mercado de trabalho, esses fatores dificultam a mudança de comportamentos relacionados à conservação ambiental por parte dos alunos.

Precisa-se evidenciar que para acontecer o desenvolvimento da Educação Ambiental é necessário mudanças de posturas práticas que precisam estar aliado à teoria, mesmo frente às dificuldades de encontrar materiais pedagógicos na área ambiental nas escolas públicas. Nota-se que em nenhum momento os sujeitos citaram a participação dos professores na preparação de atividades pedagógicas, por nenhum dos entrevistados.

Com relação aos projetos realizados na escola, não foram evidenciados nenhum projeto ou discussões voltados à Educação Ambiental. A temática não está presente na prática pedagógica, verificado através dos planos de aula dos professores da $3^{a}$ série do Ensino Médio e através do PPP da escola. A Educação Ambiental não está vinculada aos conteúdos com aderência à questão ambiental. Pressupõe-se uma modificação na prática pedagógica, ao proporcionar atividades interdisciplinares ou a integração do conhecimento por meio de projetos que deve perpassar as disciplinas de Geografia e Biologia e envolver toda escola na proposta ambiental.

Os resultados obtidos a partir da aplicação dos questionários e com as entrevistas permite-nos tecer algumas considerações sobre as concepções que tem os sujeitos que participaram deste trabalho. As respostas dos discentes encontram subsídios no ensino formal e também refletem conhecimentos que surgem espontaneamente, adquiridos através do ensino informal, conceitos e valores que eles trazem de casa ou a partir do convívio em sociedade. Salientase que os resultados encontrados com os três grupos de alunos, $3^{\mathrm{a}}$ " $\mathrm{A}$ ", $3^{\mathrm{a}}$ "B" e $3^{\mathrm{a}}$ "EJA" foram muito próximos. 


\section{Title: Environmental Education And The Contributions Of The Teaching Of Geography And Biology}

\section{Abstract}

Environmental issues require companies to seek new ways of thinking and acting, finding new ways that ensure the ecological sustainability. Currently experiencing a period of intense transformation of the environment and man is primarily responsible for the modification of environment. Knowledge in Geography and Biology related to Environmental Education (EE) propose the development of attitudes and relevant to the relationship between humans and the environment among them values. The object of the research will be the State College Dr Vasco Gonçalves dos Reis in Urutaí (GO) with students in the 3rd grade of high school the morning and evening periods, thus we intend to discuss the contributions of the teaching of Geography and Biology relative the possibility of working with EA. The methodology consists of theoretical research, desk research and field research. The theoretical research is also based on literature review, we seek to literature available and relevant information about the topic discussed in the observation of facts as occurs in reality. The desk research included reading school documents as the Political Pedagogical Project, lesson plans for teachers of Geography and Biology of the 3rd year of high school through the SIAP (System for Teaching and Learning) and other documents that contribute to the achievement of work. The method of data collection used was based on focus group with the participation of 26 students and through questionnaires with the participation of 32 students. The questionnaire consisted of twelve questions, seven subjective and five objective questions, two of which were totally closed and three questions were asked to select and justify them. The focus group interview included nine questions related to environmental issues and related questions in the questionnaire.

Keywords: environmental education; Geography teaching; Teaching of Biology. 


\section{REFERÊNCIAS}

ALVES, V. E. L. A obra de Humboldt e sua provável influência sobre a antropologia de Franz Boas. GEOUSP - Espaço e Tempo, n.18, São Paulo (SP), 2005, p. 69-74.

BISPO, M. A. A concepç̃o de natureza na Geografia e a relação com a Educação Ambiental. Revista Terceiro Inclúido: Transdiciplinaridade e Educação Ambiental, v. 2, n. 1, Goiânia (GO), 2012, p. 49-53.

BORTOLOZZI, A.; PEREZ FlLHO, A. Diagnóstico da educacã̃o ambiental no ensino de geografia. In: BISPO, M. A. A concepção de natureza na Geografia e a relação com a Educação Ambiental, v. 2, n. 1, 2012, p. 52. BRASIL. Secretaria de Educação Fundamental. Parâmetros Curriculares Nacionais: terceiro e quarto ciclos: apresentaç̃̃o dos temas transversais, Brasilia (DF|): MEC/SEF, 1998, p.195.

BRASIL. Parâmetros Curriculares Nacionais - Ensino Médio. Ciências da Natureza, Matemática e suas Tecnologias, Braślia (DF): MEC/SEF, 2000, 75p.

CARVALHO, I. C. de M. Educação Ambiental: a formação do sujeito ecológico. 6. ed. São Paulo (SP): Cortez, 2012, 255p.

CRUZ, C. R. da. 0 espaço geográfico como categoria essencial para a constituição de uma cidadania ativa: contribuições de Paulo Freire e Milton Santos. IX ANPED SUL, Pelotas (RS), 2012, p. 3.

DAGNINO, R. de S. A Geografia de Alexander Von Humboldt: diálogos entre arte e complexidade. Revista Caminhos da Geografia, v. 9, n. 26, Uberlândia (MG), 2008, p. 70.

DARWIN, C. On the origin of species by means of natural selection or the preservation of favoured races in the struggle of life. In: CARMO, V. A. do; MARTINS, L. A. P. Charles Darwin, Alfred Russel Wallace e a seleç̃óo natural: um estudo comparativo. Revista Filosofia e História da Biologia, v.1, Campinas (SP), 2006, p. 339.

FAZENDA, I. C. A. Interdisciplinaridade: um projeto em parceria. 2. ed. São Paulo (SP): Loyola, 1993, 119p. FERREIRA, M. A. Transformismo e extinção: de Lamarck a Darwin. Tese apresentada ao Programa de Pós-Graduacção em Filosofia pela Universidade de São Paulo, São Paulo (SP), 2007, p. 37.

GUIMARÃES, S. S. M. 0 saber ambiental na formação de professores de Biologia. Tese de doutorado do Programa de pós-graduação da Faculdade de Letras da Universidade Estadual Paulista Júlio de Mesquita Filho (UNESP), Araraquara (SP), 2010, p. 58-106.

KLEEN, J. T. Ensino interdisciplinar: didática e teoria. Tradução de Inara Luiza Matim. In: FAZENDA, I. C. A. (Org.) Didática e interdisciplinaridade. 7. ed. Campinas: Papirus, 2002, p. 126.

LAYRARGUES, P. P. A resolução de problemas ambientais locais deve ser um tema gerador ou a atividade-fim da educação ambiental? In: REIGOTA, M. (org). Verde Cotidiano: o meio ambiente em discussão. Rio de Janeiro (RJ): DP\&A, 2001, p. 1-134.

LEFF, E. Epistemologia Ambiental. São Paulo (SP): Cortez, 2001a, p. 196.

LEFF, E. Saber ambiental: sustentabilidade, racionalidade, complexidade, poder. Petrópolis (RJ): Vozes, 2001b, p. 49-134.

NUNES, F. G.; SILVA, S. R. da. Geografia e Educação Ambiental: reflexões a partir das concepcões e práticas de professores da rede Estadual de Dourados (MS). Revista Boletim Gaúcho de Geografia, n. 26, Porto Alegre (RS), 2011, p. 21.

ODUM, E. P. Ecologia. Guanabara Koogan, Rio de Janeiro (RJ), 1988, 434p. 
PEDRINI, A. de G. (Org.). Educação Ambiental: reflexões e práticas contemporâneas. 3. ed: Petrópolis (RJ): Vozes, 2000, p. 15.

PERANDRÉ, E. L. C. As concepções de ensino dos (as) professores (as) e a aprendizagem dos (as) alunos (as) sobre Educação Ambiental no Ensino Médio: 0 caso de uma Escola Estadual. Dissertação de Mestrado em Educação na Universidade Católica Dom Bosco, Campo Grande (MS), 2007, 192p.

REIGOTA, M. A floresta e a escola: por uma Educação Ambiental pós-moderna. São Paulo (SP): Cortez, 1999, 167p. REIGOTA, M. 0 que é Educação Ambiental. In: NUNES, F. G.; SILVA, S. R. da. Geografia e Educação Ambiental: reflexões a partir das concepções e práticas dos professores da rede estadual de Dourados (MS). Revista Boletim Goiano de Geografia, BGG n. 36, Porto Alegre (RS), 2011, p. 17.

REZENDE, I. M. N. de, et al. Educação Ambiental e Fisiologia Humana: compreensões e práticas de professores de biologia. Alexandria - Revista de Educação em Ciência e Tecnologia, v. 6, n.3, 2013, p. 214.

SUERTEGARAY, D. M. A. Questão ambiental: produção e subordinação da natureza. In: SILVA, J. B. da. et al. Panorama da Geografia Brasileira. São Paulo (SP): Annablume, 2006, p. 27.

TAMAIO, I. 0 professor na construç̃õo do conceito de natureza: uma experiência de educação ambiental. In: NUNES, F. G.; SILVA, S. R. da. Geografia e Educação Ambiental: reflexões a partir das concepç̃oes e práticas dos professores da rede estadual de Dourados (MS). Revista Boletim Goiano de Geografia, BGG n. 36, Porto Alegre (RS), 2011 , p. 17. TOLEDO, G. S. de. Educação Ambiental nos cursos de graduaç̃ão. In: SANTOS, J. E. dos; SATO, M. A contribuição da Educação Ambiental à Esperança de Pandora. 2. ed., São Carlos (SP): RiMa, 2003, p. 127.

VALERIAS, N. Contribuiç̃ões da Biologia ao desenvolvimento da Educação Ambiental. In: SANTOS, J. E. dos; SATO, M. A contribuição da Educação Ambiental à Esperança de Pandora. 2. ed., São Carlos (SP): RiMa, 2003, p. 155. 
Seminário de Pesquisa, Pós-Graduacãoo e Inovação da Regional Catalão 